\title{
Study of Persistent Haze Pollution in Winter over Jinan (China) Based on Ground-Based and Satellite Observations
}

\author{
Hui Li ${ }^{1,2}$, Rui Shi ${ }^{3}$, Shikuan Jin ${ }^{2}$ (D), Weiyan Wang ${ }^{2}$, Ruonan Fan ${ }^{2}$, Yiqun Zhang ${ }^{2}$, Boming Liu ${ }^{2}$, Peitao Zhao ${ }^{4}$, \\ Wei Gong ${ }^{5}$ and Yuefeng Zhao ${ }^{1, *}$
}

1 Shandong Provincial Engineering and Technical Center of Light Manipulations \& Shandong Provincial Key Laboratory of Optics and Photonic Device, School of Physics and Electronics, Shandong Normal University, Jinan 250014, China; lihuilmars@whu.edu.cn

2 State Key Laboratory of Information Engineering in Surveying, Mapping and Remote Sensing (LIESMARS), Wuhan University, Wuhan 430072, China; jinsk@whu.edu.cn (S.J.); weiyanwang@whu.edu.cn (W.W.); fanruonan@whu.edu.cn (R.F.); zhangyq@whu.edu.cn (Y.Z.); liuboming@whu.edu.cn (B.L.)

3 Shandong Provincial Lunan Geo-Engineering Exploration Institute (The Second Geological Brigade of Shandong Provincial Bureau of Geology \& Mineral Resources), Jining 272100, China; 2008202050090@whu.edu.cn

4 Meteorological Observation Centre, China Meteorological Administration, Beijing 100081, China; zhaopt@cma.gov.cn

5 School of Electronic Information, Wuhan University, Wuhan 430072, China; weigong@whu.edu.cn

* Correspondence: yuefengzhao@sdnu.edu.cn

Citation: Li, H.; Shi, R.; Jin, S.; Wang, W.; Fan, R.; Zhang, Y.; Liu, B.; Zhao, P.; Gong, W.; Zhao, Y. Study of Persistent Haze Pollution in Winter over Jinan (China) Based on Ground-Based and Satellite Observations. Remote Sens. 2021, 13, 4862. https://doi.org/ $10.3390 /$ rs13234862

Academic Editor: Ramesh P. Singh

Received: 30 September 2021

Accepted: 22 November 2021

Published: 30 November 2021

Publisher's Note: MDPI stays neutral with regard to jurisdictional claims in published maps and institutional affiliations.

Copyright: (c) 2021 by the authors. Licensee MDPI, Basel, Switzerland. This article is an open access article distributed under the terms and conditions of the Creative Commons Attribution (CC BY) license (https:/ / creativecommons.org/licenses/by/ $4.0 /)$.

\begin{abstract}
A comprehensive study of the formation process of haze events in the Jinan area of China during winter is conducted based on the ground-based and satellite observation data from 1 December 2020 to 12 January 2021. According to variation of pollutant concentrations, two typical types of haze pollution are found in the Jinan area. During the type 1 haze pollution, the $\mathrm{PM}_{2.5}$ concentrations are greater than $75 \mu \mathrm{gm}^{-3}$ and less than $115 \mu \mathrm{gm}^{-3}$ with a short duration. The haze is mainly caused by local pollutant emissions and the accumulation of pollutants transported from areas around Jinan. By contrast, type 2 haze pollution episodes have a long duration and peak $\mathrm{PM}_{2.5}$ concentrations between $150 \mu \mathrm{gm}^{-3}$ and $250 \mu \mathrm{gm}^{-3}$, which is considered heavy pollution. Type 2 haze pollution is mainly caused by a mixture of long-range transported dust with locally emitted pollutants. Moreover, the unfavorable meteorological factors such as stable inversion layer, continuous cold high-pressure system, high relative humidity, and low wind speed play an important role in the formation of both types of haze pollution. In addition, there are significant photochemical processes during the haze pollutions. According to satellite data, the AOD in Jinan and surrounding areas is maintained at a high-level during haze pollution. It indicates that the local pollution is often accompanied by regional pollution during haze pollution events. This study reveals the formation process of haze pollution and promotes the study of regional climate change, which can provide guidance to the government in the prevention and control of haze pollution in East China.
\end{abstract}

Keywords: haze pollution; satellite; lidar; dust transport; East China

\section{Introduction}

With the rapid development of China's economy, accelerated urbanization and expansion of industry, the problem of air pollution is becoming increasingly serious $[1,2]$. Especially in the autumn and winter seasons, widespread and persistent air pollution frequently occur in the central-eastern part of China, affecting the atmospheric environment quality and endangering human health [3-6]. Therefore, the causes of air pollution need to be analyzed and summarized to provide reference for the early warning of heavy polluted weather and air pollution prevention and control.

Many studies have been carried out to investigate the air pollution in China. Xiong et al. [7] collected PM 2.5 samples simultaneously in 2011 and 2012 at three locations in Wuhan indus- 
trial park, Wuhan city center and Wuhan botanical garden, respectively. The $\mathrm{PM}_{2.5}$ concentrations at these monitoring sites were far more than the World Health Organization (WHO) standards and the Chinese air quality standards. The main components of $\mathrm{PM}_{2.5}$ at each monitoring site varied with the seasons. This study also found that the main sources of carbon emissions were motor vehicle emissions, coal combustion, meat cooking and biomass combustion. Gautam et al. [8,9] analyzed the influences of winter haze on fog/low cloud and the holes in fog over the Indo-Gangetic (IG) plain based on the satellite data. They found that the fine mode aerosols are dominate in winter haze and are significantly coupled with fog formation over the IG Plain. The high aerosol loading and high black carbon concentrations resulted in significantly less fog/low clouds in the winter of 2004-2005 than in previous years. Meanwhile, the extent of fog holes appears highly correlated with city populations in fog-prevalent regions of Asia, Europe and the United States. Furthermore, to continuously monitor the spatial and temporal characteristics of fog and haze, Patil et al. [10] developed an automated web-based fog monitoring system over the IG Plain using multi-spectral radiances and aerosol/cloud retrievals from Terra/Aqua MODIS data. Galindo et al. [11] monitored the concentrations of $\mathrm{PM}_{1}, \mathrm{PM}_{2.5}, \mathrm{PM}_{10}$ and related inorganic ions in the city of Elche in southeastern Spain, between October 2008 to October 2009. Annual concentrations of $\mathrm{PM}_{2.5}$ and $\mathrm{PM}_{10}$ were found to decrease in different degrees relative to the period from 2004 to 2005 , respectively. This is mainly due to a significant decrease in $\mathrm{SO}_{2}$ emissions, increased precipitation and reduced construction activities. Tao et al. [12] provided the first large-scale and long-term observations of haze in the North China Plain region by integrating satellite observations, ground-based measurements, and meteorological data. They found that haze clouds are non-uniform in both vertical layer and horizontal distribution, leading to discrepancies between ground-based measurements and satellite observations. The occurrence of most haze clouds is not significantly correlated with local pollution. These studies are essential for understanding and monitoring variation in air pollutant concentrations.

With further research, many studies were focused on the formation process of air pollution [13-15]. Some studies indicated that the high emissions of urban pollutants and the long-range dust transport were key factors influencing the formation of air pollution events [16-18]. By analyzing a severe air pollution event in Wuhan in January 2015, Liu et al. [19] found that the pressure and the accumulation of pollutants were the two main causes of continuous haze formation. Then, dust transport and local anthropogenic pollutant emissions promoted the accumulation of pollutants, resulting in continuous haze pollution. Tao et al. [20] investigated the spatial variation, vertical structure, optical properties and formation process of yellow haze clouds using multi-satellite observations, ground measurements and meteorological data. Meanwhile, Tang et al. [21] analyzed the characteristics and formation of a haze-fog-dust event that occurred in North China and emphasized the effect of dust transport on regional environmental pollution during the autumn and the winter. Moreover, He et al. [22] studied the vertical distribution, horizontal extent and optical properties of dust in Wuhan area using polarized lidar and Cloud-Aerosol Lidar and Infrared Pathfinder Satellite Observations (CALIPSO) and found that the dust layer occurs at an altitude of about $1.4-3.5 \mathrm{~km}$. The dust layer is lower in winter due to the lower tropospheric inversion temperature and hygroscopic growth under proper relative humidity conditions. These studies improve our understanding of the sources and formation process of air pollution. However, as one of the most serious air pollution cities among the cities in China $[23,24]$, there are few studies on the formation and characteristics of haze pollution in Jinan. To better grasp the pattern of heavy pollution weather occurrence and provide reference for the local government to introduce relevant environmental policies in a timely manner, it is urgent and necessary to study the sources, composition and formation process of the persistent heavy pollution occurring in Jinan area.

A comprehensive study of the sources and formation of severe winter haze pollution events in the Jinan region is conducted based on the ground-based and satellite data from 1 December 2020 to 12 January 2021. First, the variation of surface pollutant concentrations and meteorological conditions is studied using pollutant monitoring data and meteoro- 
logical data from ground-based air observations. Secondly, the vertical characteristics of the atmospheric temperatures and aerosol extinction coefficients are analyzed. Finally, the sources and formation processes of pollutant events are explained based on Hybrid Single Particle Lagrangian Integrated Trajectory (HYSPLIT) backward trajectory model, CALIPSO data, and ground-based lidar detection data. Meanwhile, the regional pollution characteristics of the winter pollution events are verified using MODIS satellite data.

\section{Stations and Data}

\subsection{Observation Site}

Jinan is the capital city of Shandong Province, located in the central-western part of the province. The topography is high in the south and low in the north (Figure 1) [25]. According to the radiosonde data, $\mathrm{Li}$ et al. [26] found that the mixed layer height in Jinan is low, and the diffusion capacity of the atmosphere is poor. It leads to the accumulation of pollutants and frequent air pollution events in winter [27,28]. Figure 2 shows the MODIS true color images during the air pollution event from December 2020 to January 2021. As seen in Figure 2, the ground is covered by haze pollution. Long-term exposure to haze pollution can cause important effects on human health, such as damage to the respiratory and cardiovascular systems [29]. Therefore, it is essential to study the formation and characteristics of haze pollution in the Jinan area.

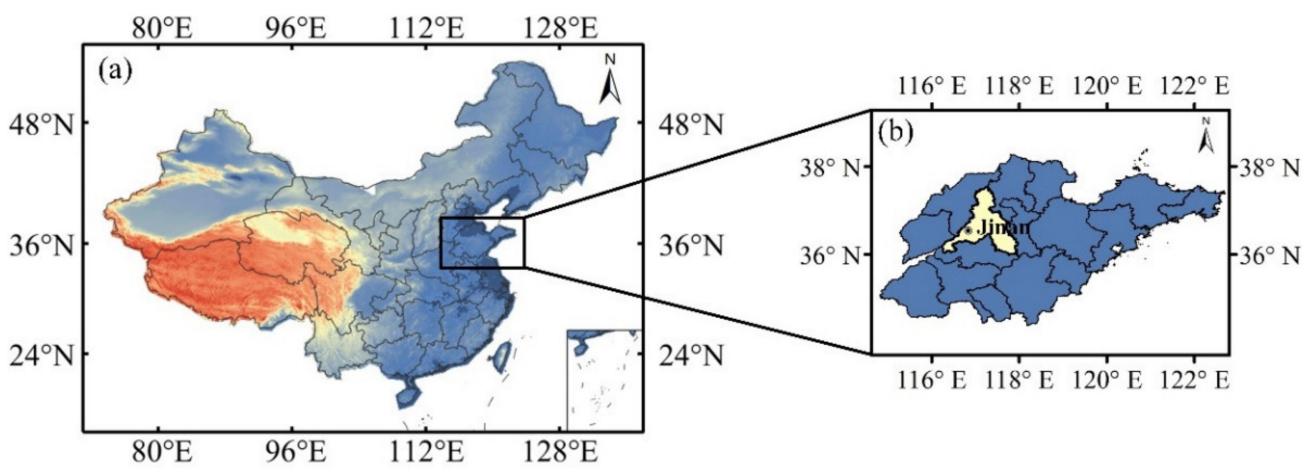

Figure 1. $(\mathbf{a}, \mathbf{b})$ Geography of Jinan area.
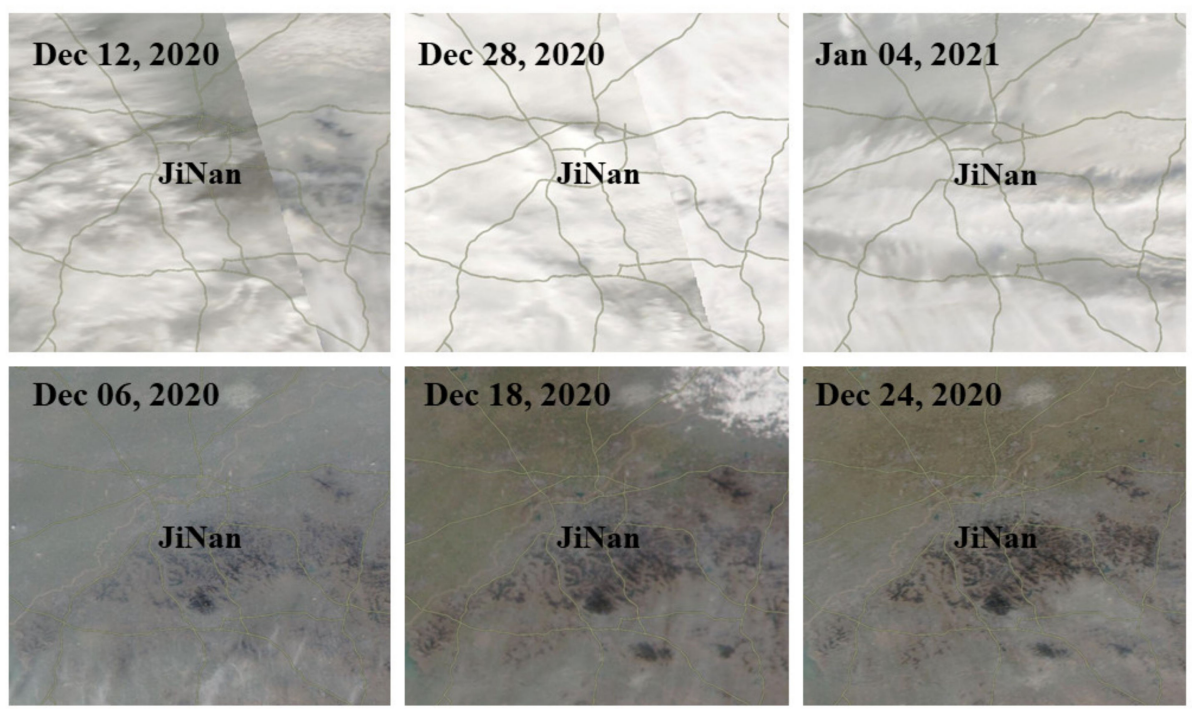

Figure 2. MODIS Aqua $1 \mathrm{~km}$ true-color images on 6, 12, 18, 24, 28 December 2020 and 4 January 2021, during the haze pollution events. 


\subsection{Ground-Based Data}

A micro pulse lidar (MPL) system was used to obtain the vertical profile of aerosol extinction coefficients. The MPL system is located on the top floor of the College of Physics and Electronic Science of Shandong Normal University $\left(116^{\circ} 50^{\prime} \mathrm{E}, 36^{\circ} 32^{\prime} \mathrm{N}\right)$. The laser emits a $532 \mathrm{~nm}$ wavelength beam. The pulse output energy and repetition frequency are $1 \mathrm{~mJ}$ and $2000 \mathrm{~Hz}$, respectively. The vertical resolution of the MPL is $7.5 \mathrm{~m}$, and the temporal resolution is $5 \mathrm{~min}$. The MPL system can obtain the data including the extinction coefficient, declination ratio, signal-to-noise ratio etc. The extinction coefficient data used in here is collected from 1 December to 31 December 2020 and 7 January to 12 January 2021.

The hourly meteorological data and radiosonde data used in this study were provided by the Bureau of Meteorology (http:/ / data.cma.cn, accessed on 1 July 2021). It is located at $117^{\circ} 00^{\prime} \mathrm{E}, 36^{\circ} 36^{\prime} \mathrm{N}, 170 \mathrm{~m}$ above sea level, and $16 \mathrm{~km}$ northeast of the lidar measurement site. The meteorological data including hourly values of temperature (Temp), relative humidity $(\mathrm{RH})$, atmospheric pressure, wind direction (WD) and wind speed (WS) in stations and cities. The radiosonde data were obtained from the radiosonde balloons launches at Jinan at 0800 and 2000 local time (LT) during the study period. The radiosonde data including vertical information of temperature, $\mathrm{RH}$, WS, etc. Its vertical resolution is $1 \mathrm{~m}$. The meteorological and radiosonde temperature data used in our research is collected from 1 December 2020 to 12 January 2021.

The concentrations of PM2.5 and gaseous pollutants were also provided by the Bureau of Meteorology (http:/ / data.cma.cn, accessed on 1 July 2021). It can provide hourly values of $\mathrm{PM}_{2.5}, \mathrm{PM}_{10}, \mathrm{CO}, \mathrm{NO}_{2}, \mathrm{SO}_{2}, \mathrm{O}_{3}$, etc. The concentration data were also collected from 1 December 2020 to 12 January 2021.

\subsection{Satellite Observations}

CALIPSO is a new type satellite of three-dimensional observation of the Earth's cloud cover and aerosols [30]. CALIPSO provides global cloud and aerosol observations. These products can be used to assess the radiative impact of clouds and aerosols, thereby improving predictions of future climate change [31]. CALIPSO can detect aerosol vertical extinction profiles and classify aerosols into six subtypes based on aerosol height, optical information, etc. The aerosols subtypes include smoke, dust, contaminated dust (dust and smoke), clean and contaminated continents and clean oceans [32]. The CALIPSO EXPEDITED Browse Images can provide the color-modulated, altitude-time images of CALIPSO attenuated backscatter, aerosol subtype, etc. The $532 \mathrm{~nm}$ attenuated backscatter and aerosol subtype image from CAL_LID_L1_Exp-Prov-V3-41 product for 05, 11, 18, 24 and 28 December 2020 and 4 January 2021 Coordinated Universal Time (UTC) are used in this study.

The MODIS on board the morning satellite Terra and afternoon satellite Aqua provides long-term observations of changes in the atmosphere and the Earth's environment [33]. MODIS can provide a variety of data products such as aerosol, cloud properties, land surface reflectance, etc. [34]. Since Jinan is an inland city, previous studies have shown that the Deep Blue algorithm has superior performance over the Dark Target algorithm for aerosol optical depth (AOD) inversion in inland cities in China [35]. Hence, the deep-blue AOD at $550 \mathrm{~nm}$ data of MYD04_L2 product for 05, 11, 18, 24 and 28 December and April 2020 and January 2021 (UTC) in Jinan area are used in this paper.

\subsection{Other Data}

The $24 \mathrm{~h}$ backward trajectories arriving at Jinan are calculated using HYSPLIT model [36] of the National Oceanic and Atmospheric Administration (NOAA) to trace the source of contaminated aerosols. The HYSPLIT model is divided into a web version and a software version, and the HYSPLIT model used in this study is the web version [37]. The $24 \mathrm{~h}$ backscatter trajectory models at 2300 UTC on 5 December 2020, 0300 UTC on 18 December 2020, 0400 UTC on 24 December 2020 at 0.1, 0.3, $0.5 \mathrm{~km}$ height and 1800 UTC on 11 December 
2020, 1000 UTC on 28 December 2020, and 0500 UTC on 4 January 2021 at 0.5, 1.5 and $2.5 \mathrm{~km}$ height are used in this paper.

\section{Results and Discussion}

In this section, the variations of major pollutants concentration and meteorological conditions during the haze pollution are firstly investigated. The vertical distribution of temperature and aerosol extinction coefficients during the haze pollution are then presented. Finally, the formation process and regional pollution characteristics of haze pollution are analyzed.

\subsection{Overview of Winter Haze Pollution in Jinan}

Figure 3 presents the hourly concentrations of $\mathrm{PM}_{2.5}, \mathrm{PM}_{10}, \mathrm{CO}, \mathrm{NO}_{2}, \mathrm{SO}_{2}$ and $\mathrm{O}_{3}$ in the Jinan area during the period from 1 December 2020 to 12 January 2021. According to the latest air quality standards [38], $24 \mathrm{~h}$ average $\mathrm{PM}_{2.5}$ concentration over $75 \mathrm{\mu gm}^{-3}$ indicates the existence of air pollution. $24 \mathrm{~h}$ average $\mathrm{PM}_{2.5}$ concentration greater than $75 \mu \mathrm{gm}^{-3}$ less than $115 \mu \mathrm{gm}^{-3}$ for light pollution, $115 \mu \mathrm{g} / \mathrm{m}^{-3}$ to $150 \mu \mathrm{g} / \mathrm{m}^{-3}$ for moderate pollution, $115 \mathrm{\mu gm}^{-3}$ to $150 \mathrm{\mu gm}^{-3}$ for heavy pollution and greater than $250 \mathrm{\mu gm}^{-3}$ indicates the occurrence of serious pollution. Several haze pollution events occurred during this period. As illustrated in Figure 3a, six haze pollution events can be seen based on the variation of major pollutants concentrations. According to the variation of pollutant concentrations, it can be noticed that there are two typical haze pollution events in the Jinan area. The type and duration of haze pollution events are shown in Table 1. Pollution event 1, 3 and 4 (type 1) exhibited significant differences in duration and pollutant concentrations of pollutants compared with event 2, 5 and 6 (type 2) (Figure 3a). The duration of type 1 haze pollution is relatively short with $\mathrm{PM}_{2.5}$ below $115 \mu \mathrm{gm}^{-3}$, which is light pollution. Type 2 haze pollution have a long duration and peak $\mathrm{PM}_{2.5}$ concentrations between $150 \mu \mathrm{\mu gm}^{-3}$ and $250 \mathrm{\mu gm}^{-3}$, which is heavy pollution. It is noteworthy that during type 2 haze pollution, the peak $\mathrm{PM}_{10}$ concentrations all exceeded $200 \mathrm{\mu gm}^{-3}$ (Figure 3a). The concentrations of gaseous pollutants such as $\mathrm{CO}, \mathrm{NO}_{2}$ and $\mathrm{SO}_{2}$ increase significantly during both type 1 and type 2 haze pollution (Figure $3 b, d$ ). The trends in $\mathrm{CO}$ and $\mathrm{NO}_{2}$ concentrations are consistent with $\mathrm{PM}_{2.5}$, indicating a significant influence of local accumulation of urban emissions on the formation of haze pollution (Figure $3 b, c)$. This is consistent with the results reported by Gao et al. [39] who indicated that elevated concentrations of aerosols and their chemical constituents on haze days were associated with transport emissions of perceived source pollutants around the study area. By investigating haze pollution events with low visibility in the northern Indian city of Chandigarh, Ravindra et al. [40] found a high correlation between high $\mathrm{PM}_{2.5}$ concentrations and $\mathrm{CO}$ and $\mathrm{No}_{\mathrm{x}}$ during haze pollution, indicating that the sources are mainly biomass burning, fossil fuel combustion, and vehicle exhaust emissions. The concentration of $\mathrm{O}_{3}$ shows a significant daily variation, with high midday concentrations and low nighttime concentrations, indicating significant photochemical processes [41-43]. 

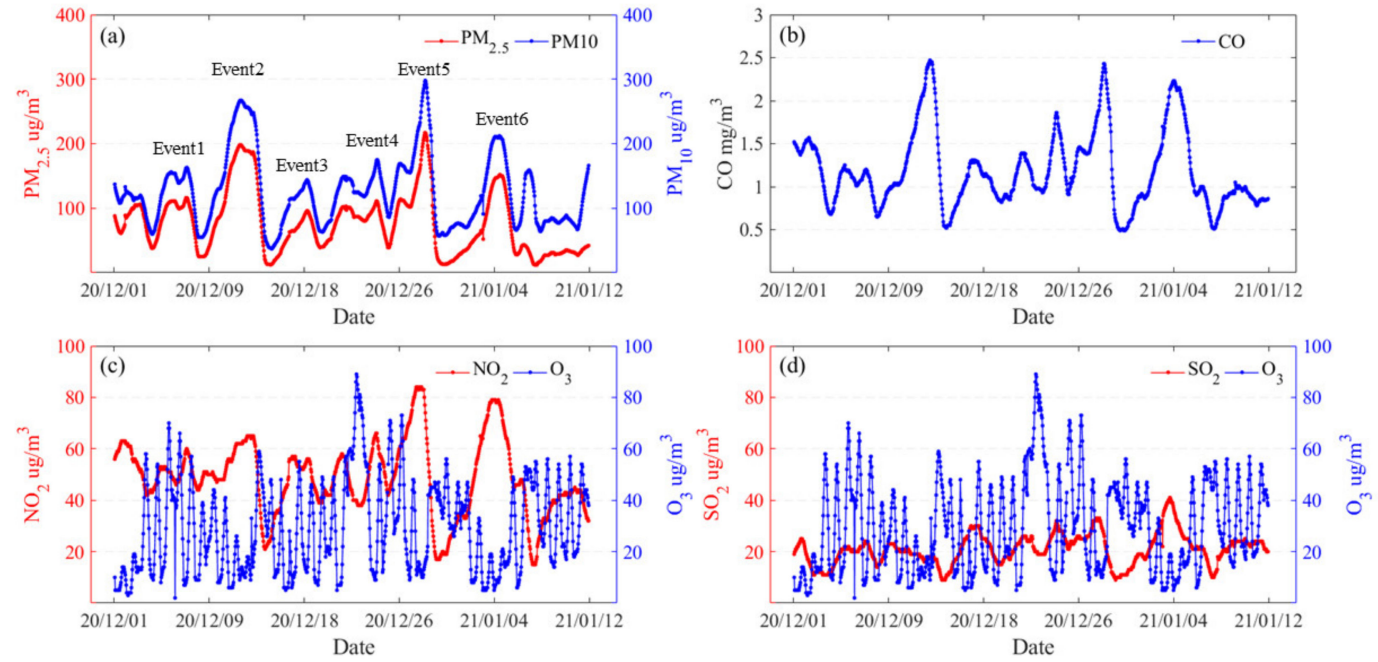

Figure 3. (a-d) Concentrations of $\mathrm{PM}_{2.5}, \mathrm{PM}_{10}, \mathrm{SO}_{2}, \mathrm{CO}, \mathrm{O}_{3}$ and $\mathrm{NO}_{2}$ in Jinan from 1 December 2020 to 12 January 2021. Several serious haze pollution events are marked.

Table 1. Information of the haze pollution events in Jinan area.

\begin{tabular}{cccc}
\hline $\begin{array}{c}\text { Event } \\
\text { Type }\end{array}$ & Event Number & Duration (LT) & $\begin{array}{c}\mathbf{M a x ~ P M}_{\mathbf{2 . 5}} \\
\boldsymbol{\mu g m}^{-3} \mathbf{)}\end{array}$ \\
\hline \multirow{3}{*}{ Type 1 } & Event 1 & 01:00 5 December 2020-21:00 7 December 2020 & 111 \\
& Event 3 & 18:00 17 December 2020-21:00 18 December 2020 & 103 \\
& Event 4 & 22:00 20 December 2020-00:00 25 December 2020 & 111 \\
\hline \multirow{3}{*}{ Type 2 } & Event 2 & 20:00 9 December 2020-21:00 13 December 2020 & 198 \\
& Event 5 & 03:00 26 December 2020-15:00 29 December 2020 & 217 \\
& Event 6 & 05:00 3 January 2021-11:00 5 January 2021 & 152 \\
\hline
\end{tabular}

To investigate the effect of meteorological conditions on the variation of air quality, the temperature, $\mathrm{RH}, \mathrm{WS}, \mathrm{WD}$ and pressure during the haze pollution event are analyzed in Figure 4. The surface temperature during haze pollution was low, which was all below $10^{\circ} \mathrm{C}$ (Figure 4a). As illustrated in Figure $4 \mathrm{~b}$, the $\mathrm{RH}$ is relatively high before the haze pollution event, with local peaks greater than $80 \%$. The trends of $\mathrm{PM}_{2.5}$ and $\mathrm{RH}$ are very consistent, but there is a significant lag. This indicates that high $\mathrm{RH}$ can promote the hygroscopic growth of aerosol particles. Yang et al. [44] also indicated that high RH would promote the hygroscopic growth of aerosol particles and increase the water soluble of $\mathrm{SO}_{2}$ and $\mathrm{NO}_{2}$, resulting in the formation of secondary pollutants such as sulfate and nitrates. The WS (Figure 4c) is below $4 \mathrm{~m} / \mathrm{s}$ during the haze pollution events, except during event 5, when the WS is greater than $6 \mathrm{~m} / \mathrm{s}$. It is also evident from Figure $4 \mathrm{c}$ that the increase in WS is accompanied by a decrease in $\mathrm{PM}_{2.5}$ concentration during event 5 . It can be observed that strong winds can accelerate the diffusion of pollutants and thus lead to the dissipation of haze pollution events. Gui et al. [45] indicated that low WS and stable stratification lead to poor aerosol diffusion and provide favorable secondary transformation conditions that ultimately lead to severe haze events. The atmospheric state remains at a high-pressure system $(1035 \mathrm{hPa})$ during the haze pollution event as illustrated in Figure 4d. High pressure greatly restricts the flow of the atmosphere, leading to persistent air pollution and contributing significantly to the formation of haze events. In their study of the characteristics and formation mechanisms of continuous haze in China, Yang et al. [46] found that a weak high-pressure system dominates during the haze period, leading to low surface wind speeds and relatively stagnant weather, which is consistent with our findings. Pachauri et al. [47] analyzed total suspended particulate (TSP), pollutant gases and meteorological parameters collected from four severe pollution events in Agra. They found that the high TSP concentrations and high pollutant gases concentrations may 
be attributed to increased combustion sources and stagnant meteorological conditions (low mixing layer height, low temperature, and high $\mathrm{RH}$ ).
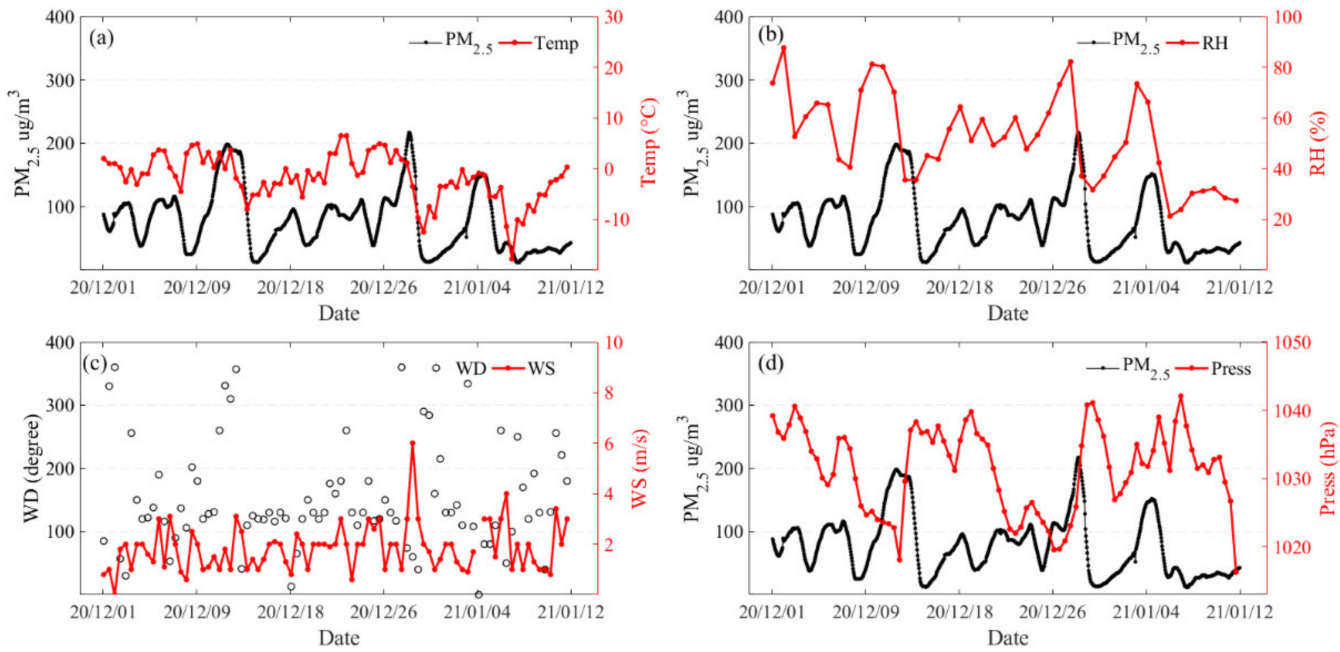

Figure 4. Variations of (a) $\mathrm{PM}_{2.5}$ and Temperature; (b) $\mathrm{PM}_{2.5}$ and $\mathrm{RH}$; (c) WD and WS; (d) $\mathrm{PM}_{2.5}$ and pressure in Jinan from 1 December 2020 to 12 January 2021.

\subsection{Vertical Characteristics during Haze Pollution}

To better investigate the vertical characteristics of the atmosphere during haze pollution, the vertical distributions of temperatures and aerosol extinction coefficients were analyzed. Figure $5 \mathrm{a}, \mathrm{b}$ show the temperature profiles for type 2 and type 1 haze pollution, respectively. It indicates that there is a strong inversion layer during both type 1 and type 2 haze pollution. The inversion layer height is below $0.3 \mathrm{~km}$ for all haze pollution events except for event 5 , where the inversion layer height is around $1 \mathrm{~km}$. The above findings suggest that the accumulation of pollutants is more favorable under continuous inversion layer conditions. In a study of pollution in northern Chinese cities during the dust season, Tao et al. [48] demonstrated that a continuous strong near-surface inversion greatly increased $\mathrm{PM}_{2.5}$ concentrations.
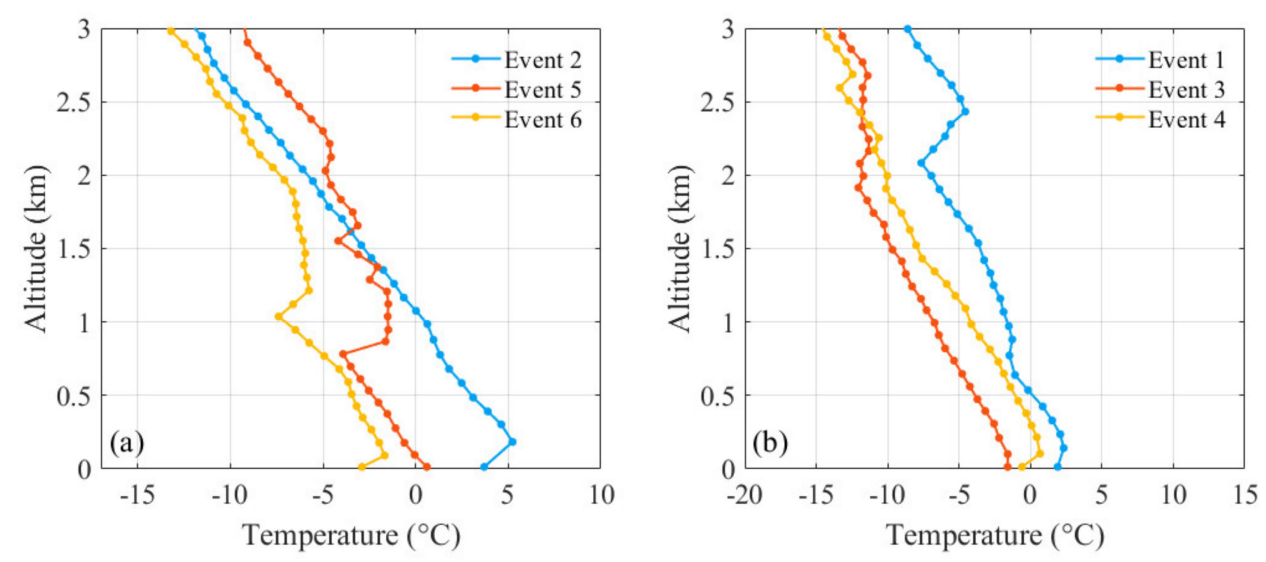

Figure 5. Vertical profiles of temperature in Jinan during the (a) type 2; (b) type 1 haze pollution events.

The vertical distributions of aerosol extinction coefficients during the haze pollution event in Jinan area were analyzed by lidar observation, as shown in Figure 6. Figure 6a,b illustrate the extinction coefficient profiles at event 2 and 5 during type 2 pollution. Due to the lidar equipment was maintained from 1 January to 7 January 2021, the extinction coefficients profile for event 6 are missing. Figure $6 c, e$ illustrate the extinction coefficient 
profiles at event 1, 3 and 4 during type 1 pollution. During the type 2 haze pollution (Figure $6 \mathrm{a}, \mathrm{b}$ ), the aerosol layer observed by the lidar system is concentrated between $1-1.5 \mathrm{~km}$ and $0.3-0.6 \mathrm{~km}$. The high aerosol extinction coefficient indicates an accumulation of pollutants at both low and high altitudes. It indicates that type 2 haze pollution may be due to a combination of external transport and local emissions. By contrast, the aerosol layer of type 1 haze pollution gathers within $1 \mathrm{~km}$. Moreover, the aerosol extinction coefficient is relatively low, indicating that the air pollution was mainly affect by local emissions the during the type 1 haze pollution (Figure $6 c, e$ ). The pollutant concentrations trended upward on 11 December 2020 and peaked at 06:00 (LT) on 11 December (Figure 6d) during the haze pollution event 2 . It trended downward on 12 December mainly due to the decrease in RH and enhanced surface WS on 12 December resulting in the diffusion of pollutants. The trend of other haze pollution events is consistent with event 2. Liu et al. [49] also indicated that the high WS and low RH were conducive to spreading the pollutants.
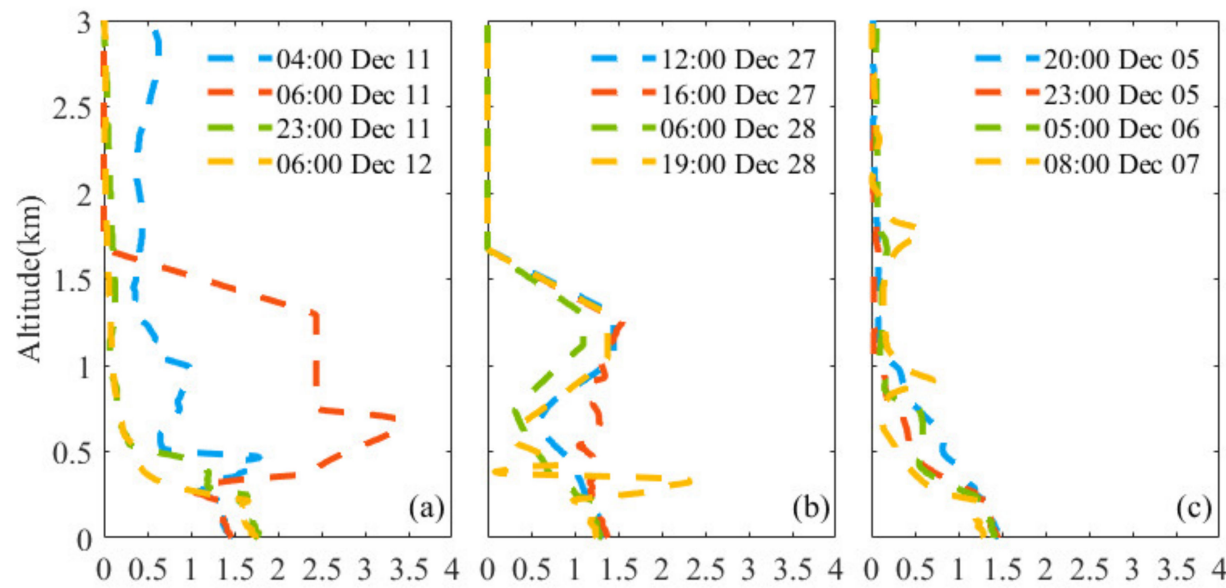

Aerosol Extinction $\left(\mathrm{km}^{-1} \mathrm{sr}^{-1}\right)$ Aerosol Extinction $\left(\mathrm{km}^{-1} \mathrm{sr}^{-1}\right)$ Aerosol Extinction $\left(\mathrm{km}^{-1} \mathrm{sr}^{-1}\right)$

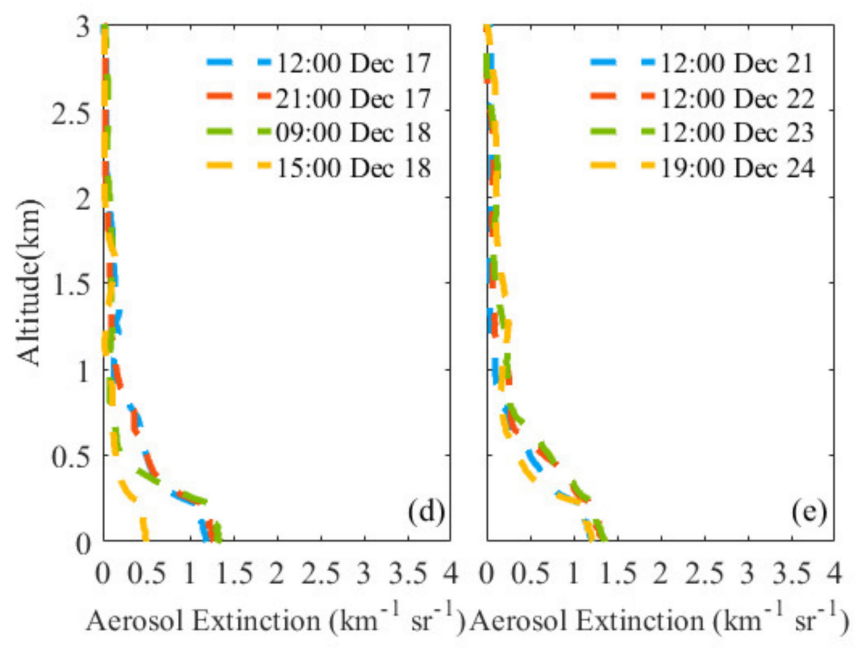

Figure 6. Vertical profile of aerosol extinction in Jinan during the haze pollution (a) event 2; (b) event 5; (c) event 1 ; (d) event 3 ; (e) event 4 .

\subsection{Formation Process of Haze Pollution in Jinan Area}

In this section, to investigate the causes of aerosol accumulation in different types of haze pollution events, the aerosol sources in the period of different haze pollution events were investigated using the HYSPLIT $24 \mathrm{~h}$ backward trajectory model, MODIS and CALIPSO observations.

Figure 7a illustrates the HYSPLIT $24 \mathrm{~h}$ backward trajectory model (top), CALIPSO 532 $\mathrm{nm}$ total attenuated backscatter (middle) and aerosol subtype (bottom) images during haze 
pollution event 2. In Figure 7a (top), the red, blue and green lines represent the backscatter trajectories at $0.5,1.5$ and $2.5 \mathrm{~km}$ height, respectively. The black line shows the CALIPSO ground tracks. It can be seen in it that the air masses at $0.5 \mathrm{~km}$ altitude mainly come from the surrounding province of Jinan, Henan province. The air masses at $1.5 \mathrm{~km}$ and $2.5 \mathrm{~km}$ altitude mainly come from the long-distance transport in the northwest of Inner Mongolia and Gansu province. Then, the CALIPSO measured the atmospheric profiles of long-range transported air masses in Inner Mongolia (Figure 7a middle and bottom). The results indicated that the pollution layer is thicker, up to $2-3 \mathrm{~km}$. It also showed that the air mass transport at $1.5 \mathrm{~km}$ and $2.5 \mathrm{~km}$ altitude in the HYSPLIT model is indeed contaminated. The dust particles were concentrated at $2-5 \mathrm{~km}$. The aerosol subtypes at this time are mainly dust and polluted dust, accompanied by a small amount of smoke. Combined with the analysis of backscatter trajectory, it can be concluded that there is basically no dust pollution below $0.5 \mathrm{~km}$, and there is long-range dust transport at $1.5 \mathrm{~km}$ and $2.5 \mathrm{~km}$ altitude. In summary, the haze pollution event 2 in Jinan area is mainly a mixture of long-range transported dust with locally emitted pollutants. Figure $7 \mathrm{~b}$ illustrates that long-range transport also exists for haze pollution event 5 , but the type of pollutant cannot be determined due to the non-overlapping CALIPSO trajectories and cloud cover occlusion. Event 6 is consistent with event 2, with long-range transport of pollutants observed during the period (Figure 7c). These results indicate the cause of type 2 haze pollution may be a combination of long-range dust transport and local pollutant accumulation. Meanwhile, the inversion layer is low (Figure 5a) and the RH is high (Figure $4 \mathrm{~b}$ ) during the occurrence of type 2 haze pollution, which is conducive to the accumulation of pollutants and intensifies the formation of haze pollution. Liu et al. [19] indicated that long-distance transport of dust and local anthropogenic pollutant emissions promote the accumulation of pollutants, leading to the persistence of haze pollution. Similarly, Fu et al. [50] indicated that highaltitude air masses from Inner Mongolia have a significant influence on the formation of persistent haze complex pollution. The transport of external pollutants and the generation of anthropogenic pollutants promote the accumulation of pollutants. The aforementioned studies are consistent with our observation that the long-range transport of dust has a significant impact on type 2 haze pollution. In addition, the smoke was found to be included in the transported pollutants, suggesting that it may also be related to local heating emissions.

Since the aerosol layers of type 1 haze pollution are all clustered around $0.5 \mathrm{~km}$ (Figure 6c,e), the backscattering trajectories at $0.1,0.3$, and $0.5 \mathrm{~km}$ heights during type 1 haze pollution were analyzed and represented in red, blue and green, respectively, as shown in Figure 8 (top). Figure 8 a illustrates the 24-h backward trajectory model (top), CALIPSO $532 \mathrm{~nm}$ total attenuated backscatter (middle) and aerosol subtype (bottom) images during haze pollution event 1. It can be seen in Figure 8a that the air masses below $0.5 \mathrm{~km}$ are mainly from cities and provinces around Jinan, and there is basically no longrange transmission. Since cities and provinces around Jinan are centrally heated in winter, which may lead to a large amount of pollutant emissions. Meanwhile, CALIPSO measured the atmospheric profiles of Shijiazhuang, Zhengzhou and Beijing near the haze pollution event 1 (Figure 8a middle and bottom). Combined with the HYSPLIT backward trajectory model and CALIPSO observations, it can be obtained that the main aerosol subtypes in the vicinity of the haze pollutant event 1 transport air mass are polluted continents and dust below $0.5 \mathrm{~km}$. This indicates that event 1 haze pollution is mainly caused by winter heating pollutant emissions and the accumulation of other anthropogenic pollutants from Jinan and around cities. Figure $8 \mathrm{~b}$ illustrates that the pollutant sources during the occurrence of event 3 are also mainly transported from cities around Jinan, but the pollutant types could not be determined due to the non-overlapping CALIPSO trajectories and cloud obscuration. Event 4 is similar to event 1, where close transport of pollutants and pollutant types such as smoke are observed below $0.5 \mathrm{~km}$ (Figure 8c). Hence, combined with the above analysis, it can be concluded that the accumulation of local pollutant emissions and pollutants transported from around cities lead to type 1 haze pollution. It mainly due to the presence 
of the inversion layer (Figure 5b) and factors such as low ground WS (Figure 4c) and high pressure (Figure $4 \mathrm{~d}$ ). The accumulation of pollutants is caused by the aforementioned weather conditions that are not conducive to the dispersion of pollutants [22]. Qi et al. [51] indicated that the main causes of continuous pollution events in East China due to biomass burning are related to the transport of pollutants, local pollution emissions and weather stagnation. Zhao et al. [52] also indicated that burning biomass and coal emissions in autumn and winter had a significant effect on the aerosol extinction coefficient. Similarly, Wang et al. [53] in their study of the contribution of dust and anthropogenic sources to aerosols in northern China showed that bottom layer anthropogenic aerosols accounted for more than $80 \%$ in winter. Moreover, Wang et al. [53] indicated that aerosols have a vertical stratification feature, with mainly dust plus anthropogenic aerosols above the PBL and mainly anthropogenic aerosols in the PBL.

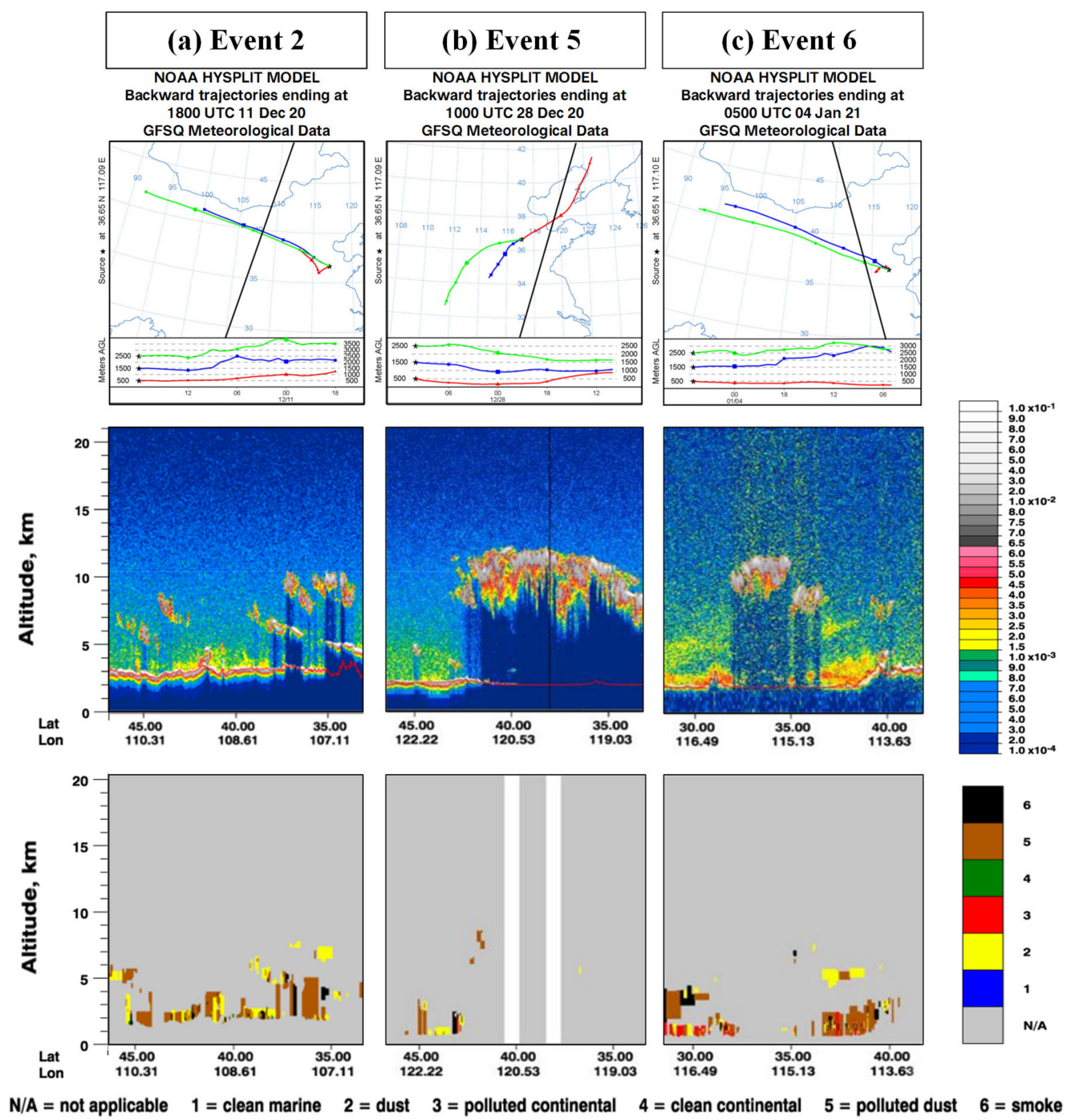

Figure 7. (a-c) HYSPLIT $24 \mathrm{~h}$ backward trajectories during type 2 haze pollution events (top), CALIPSO $532 \mathrm{~nm}$ total attenuated backscatter (middle) and aerosol subtype (bottom) during Type 2 haze pollution events. 


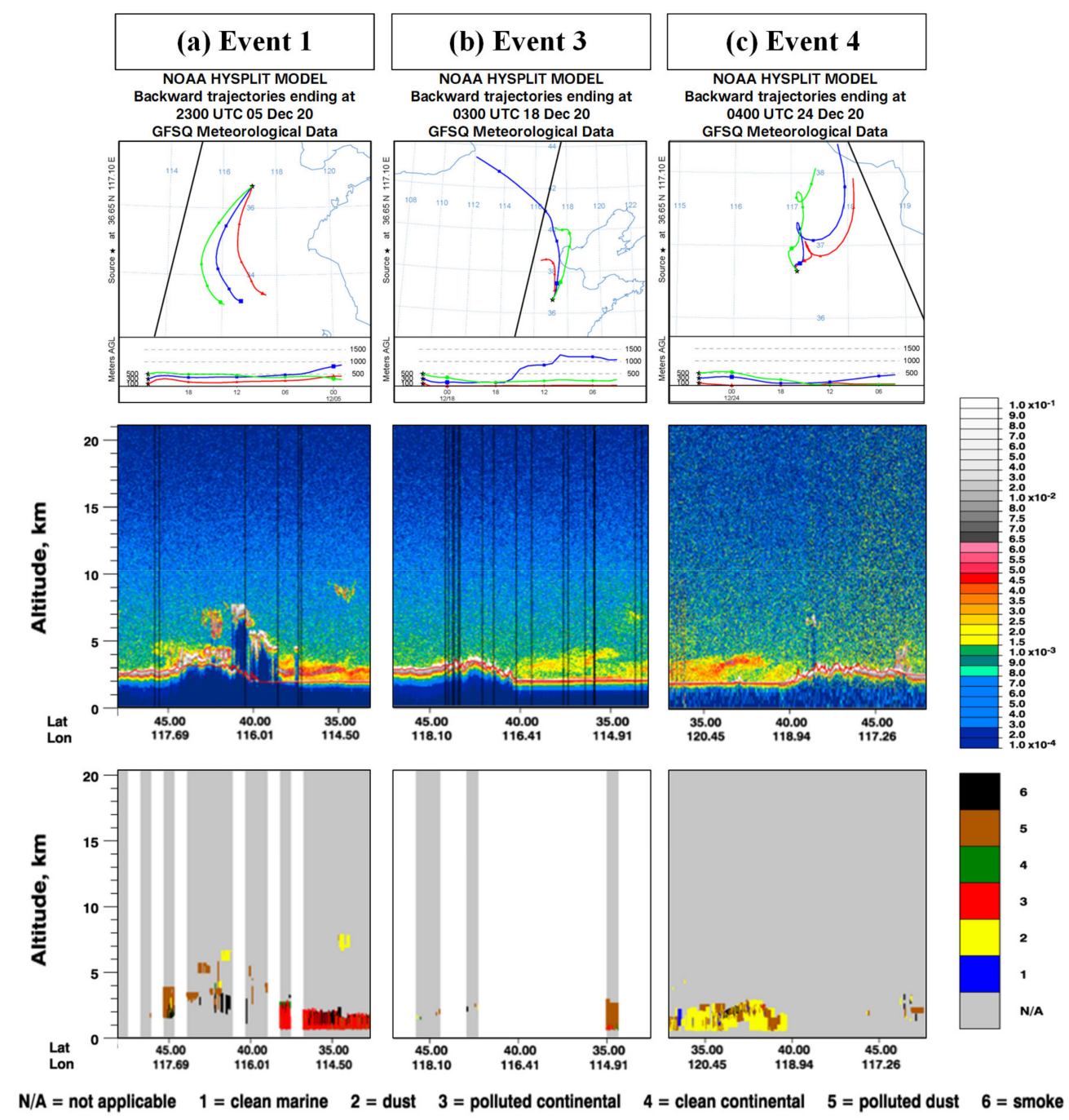

Figure 8. (a-c) HYSPLIT 24-h backward trajectories during type 1 haze pollution events (top), CALIPSO $532 \mathrm{~nm}$ total attenuated backscatter (middle) and aerosol subtype (bottom) during Type 1 haze pollution events.

Figure 9 shows the regional pollution characteristics during the type 2 and type 1 haze pollution period based on the MODIS $10 \mathrm{~km}$ deep-blue aerosol optical depth (AOD) product at $550 \mathrm{~nm}$. The black squares represent the Jinan area. AOD values for the Jinan area were not provided on 28 December 2020 (event 5) due to cloud occlusion. Figure 9 indicates that the AOD values in Jinan and its surrounding areas are at high levels during type 2 haze pollution, and even exceed 2 in some areas of Jinan. It indicates the strong extinction ability of aerosols during type 2 haze pollution, which reflects the severity of regional pollution [54]. Although the AOD during type 1 haze pollution is smaller than during type 2 haze pollution, it is still at a high level, which indicates significant near-surface pollution [55]. Meanwhile, the AOD around Jinan is at a high level when there is a haze pollution event in the Jinan area. It indicates that local pollution is often accompanied by regional pollution. Tao et al. [12] indicated that the local pollution is usually accompanied by large-scale regional pollution. 

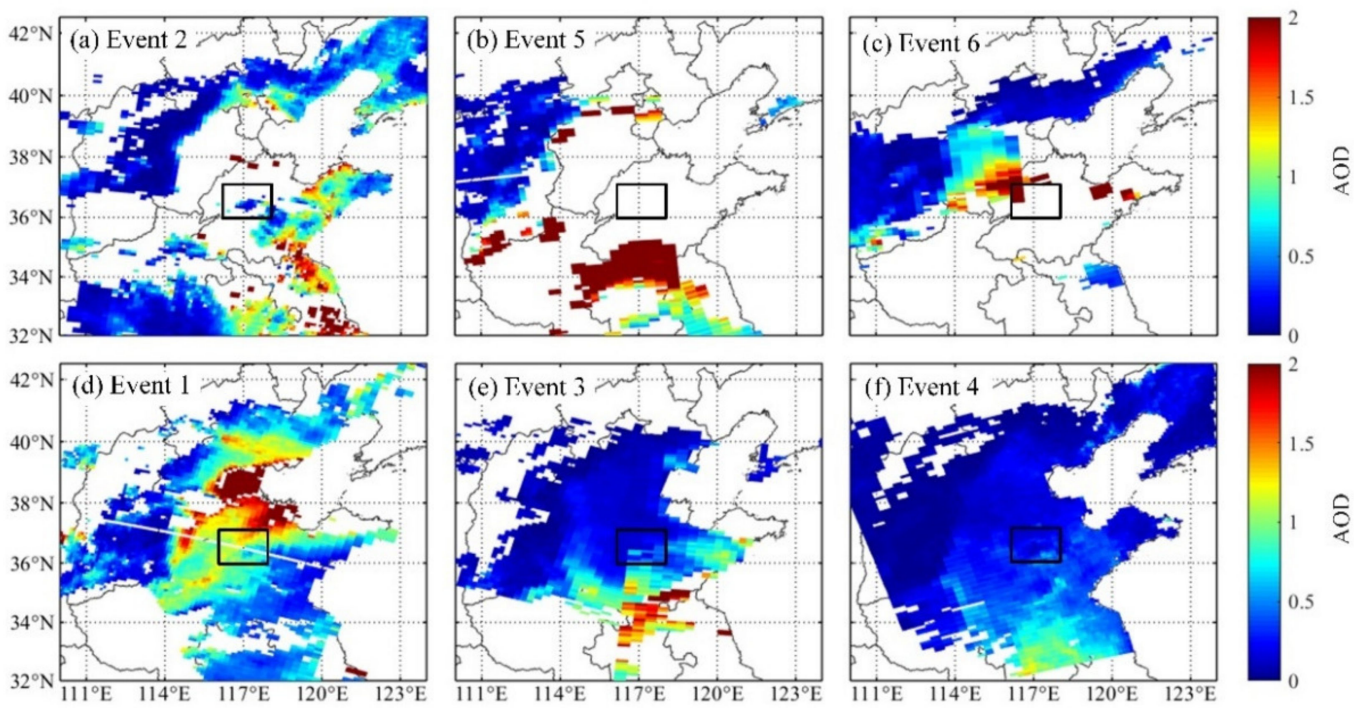

Figure 9. MODIS $10 \mathrm{~km}$ deep blue AOD at $550 \mathrm{~nm}$ in Jinan during the haze pollution (a) event2; (b) event 5; (c) event 6; (d) event 1 ; (e) event 3 ; (f) event 4 .

In general, combined with the above observations, two types of haze pollution formation in Jinan are analyzed. Type 1 haze pollution is mainly due to local transport and local emissions. At the same time, unfavorable meteorological conditions, such as low inversion layer, low ground WS and high pressure, lead to poor atmospheric dispersion conditions. Under such weather conditions, anthropogenic pollutants, motor vehicle exhaust, industrial dust and atmospheric fallout tend to accumulate, causing continuous haze pollution. Furthermore, Cheng et al. [56] indicated that the water-soluble inorganic ions (WSIIs) were the dominant chemical species during the haze pollution events. The high oxidation rate of $\mathrm{NO}_{2}$ and $\mathrm{SO}_{2}$ would generate sulfate and nitrate aerosols [57]. As illustrated in Figure 3, the levels of both $\mathrm{NO}_{2}$ (Figure 3c) and $\mathrm{SO}_{2}$ (Figure 3d) increase to varying degrees, leading to an increase in nitrate and sulfate aerosol levels during this period and accelerating the formation of hazy weather. Meanwhile, more secondary species $\left(\mathrm{SO}_{4}^{2-}, \mathrm{NO}_{3}^{-}, \mathrm{NH}_{4}^{+}\right)$in particles were generated during haze pollution events [39,46]. Pachauri et al. [47] indicated that $\mathrm{SO}_{4}^{2-}$ and $\mathrm{NO}_{3}^{-}$were the most abundant ions during the haze pollution period in Agra. They also indicated that the nitrate and sulfate increase due to stagnant weather conditions, further aggravating the formation and development of haze pollution events. By contrast, the type 2 haze pollution is mainly due to the combination of long-range transport of pollutants and local emissions. High-altitude air masses carrying dust, mixed with locally emitted pollutants, intensify the formation of haze pollution. Meanwhile the presence of low inversion layer leads to weather stagnation and higher $\mathrm{RH}$ promotes the hygroscopic growth of aerosol particles. The above weather conditions favor the accumulation of long-range transport and local emitted pollutants in the atmosphere, which eventually lead to the formation of type 2 pollution.

\section{Conclusions}

In this study, the formation process of haze events and the aerosol optical properties during the pollution period in the Jinan area of China in winter were analyzed by combining ground and satellite observations.

Two typical types of haze pollution were found in the Jinan area according to their duration, pollutant sources, and formation processes. The $\mathrm{PM}_{2.5}$ concentration is greater

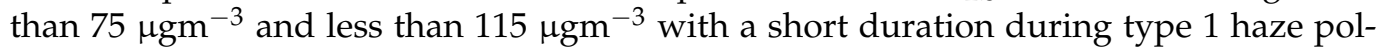
lution. By contrast, type 2 haze pollution events have a long duration and peak $\mathrm{PM}_{2.5}$ concentrations between $150 \mathrm{\mu gm}^{-3}$ and $250 \mathrm{\mu gm}^{-3}$, which is heavy pollution. Type 1 haze pollution in Jinan area is mainly caused by the accumulation of local pollutant emissions 
and pollutants transported from around cities in winter. Moreover, type 2 haze pollution is mainly a mixture of long-range transported dust with locally emitted pollutants. Nearsurface air masses mainly come from cities around Jinan, such as Zhengzhou, Shijiazhuang and Beijing, which are heated in winter. The high-altitude air masses mainly come from dust-rich areas such as Inner Mongolia and Gansu. The stable inversion layer, continuous cold high-pressure system, high relative humidity, and low wind speed are the key meteorological factors affecting the formation of both types of haze pollution events. In addition, stagnant weather conditions led to an increase in nitrates and sulfates, further contributing to the formation and development of both types of haze pollution events. The trends of $\mathrm{CO}$ and $\mathrm{NO}_{2}$ concentrations are consistent with $\mathrm{PM}_{2.5}$ concentrations, and there are significant photochemical processes during haze pollution. The AOD in Jinan and surrounding areas is maintained at a high level during the haze pollution events. It indicates that the aerosol extinction ability is strong and local pollution is often accompanied by regional pollution during haze pollution events.

This study reveals the formation process of haze pollution and promotes the study of regional climate change, which can provide guidance to the government in the prevention and control of haze pollution in East China.

Author Contributions: Conceptualization, H.L. and B.L.; methodology, B.L.; software, H.L.; validation, S.J., W.W. and R.F.; formal analysis, H.L. and Y.Z. (Yiqun Zhang); resources, W.G.; data curation, Y.Z. (Yuefeng Zhao) and P.Z.; writing—original draft preparation, H.L.; writing—review and editing, B.L.; visualization, R.S.; supervision, W.G.; project administration, W.G.; funding acquisition, Y.Z. (Yuefeng Zhao). Investigation, R.S. and Y.Z. (Yuefeng Zhao). All authors have read and agreed to the published version of the manuscript.

Funding: This research was funded by the Natural Science Foundation of Shandong Province (No. ZR2019MA028, No. ZR2020MA082), National Natural Science Foundation of China (NSFC) (No. 11974219, No. 12174227) and National Natural Science Foundation of China (No. 62002208).

Data Availability Statement: No new data were created or analyzed in this study. Data sharing is not applicable to this article.

Conflicts of Interest: The authors declare no conflict of interest.

\section{References}

1. Ren, Z.; Wan, B.; Su, F.; Gao, Q.; Zhang, Z.; Hong, Z.; Hu, F.; Cheng, S. Several characteristics of atmospheric environmental quality in China at present. Res. Environ. Sci. 2004, 17, 1-6.

2. Wang, W.; He, J.; Miao, Z.; Du, L. Space-Time Linear Mixed-Effects (STLME) model for mapping hourly fine particulate loadings in the Beijing-Tianjin-Hebei region, China. J. Clean. Prod. 2021, 292, 125993. [CrossRef]

3. Cheng, S.; Chen, D.; Li, J.; Wang, H.; Guo, X. The assessment of emission-source contributions to air quality by using a coupled MM5-ARPS-CMAQ modeling system: A case study in the Beijing metropolitan region, China. Environ. Model. Softw. 2007, 22, 1601-1616. [CrossRef]

4. Tao, M.; Chen, L.; Wang, Z.; Ma, P.; Tao, J.; Jia, S. A study of urban pollution and haze clouds over northern China during the dusty season based on satellite and surface observations. Atmos. Environ. 2014, 82, 183-192. [CrossRef]

5. Wang, Y.; Yao, L.; Wang, L.; Liu, Z.; Ji, D.; Tang, G.; Zhang, J.; Sun, Y.; Hu, B.; Xin, J. Mechanism for the formation of the January 2013 heavy haze pollution episode over central and eastern China. Sci. China Earth Sci. 2014, 57, 14-25. [CrossRef]

6. Guo, J.; Liu, B.; Gong, W.; Shi, L.; Zhang, Y.; Ma, Y.; Zhang, J.; Chen, T.; Bai, K.; Stoffelen, A. Technical note: First comparison of wind observations from ESA's satellite mission Aeolus and ground-based radar wind profiler network of China. Atmos. Chem. Phys. 2021, 21, 2945-2958. [CrossRef]

7. Xiong, Y.; Zhou, J.; Schauer, J.J.; Yu, W.; Hu, Y. Seasonal and spatial differences in source contributions to PM2. 5 in Wuhan, China. Sci. Total Environ. 2017, 577, 155-165. [CrossRef]

8. Gautam, R.; Hsu, N.C.; Kafatos, M.; Tsay, S.C. Influences of winter haze on fog/low cloud over the Indo-Gangetic plains. J. Geophys. Res. Atmos. 2007, 112, D05207. [CrossRef]

9. Gautam, R.; Singh, M.K. Urban heat island over Delhi punches holes in widespread fog in the Indo-Gangetic Plains. Geophys. Res. Lett. 2018, 45, 1114-1121. [CrossRef]

10. Patil, D.; Chourey, R.; Rizvi, S.; Singh, M.; Gautam, R. An automated fog monitoring system for the Indo-Gangetic Plains based on satellite measurements. In Proceedings of the Remote Sensing and Modeling of the Atmosphere, Oceans, and Interactions VI, New Delhi, India, 3 May 2016; p. 988226. 
11. Galindo, N.; Gil-Molto, J.; Varea, M.; Chofre, C.; Yubero, E. Seasonal and interannual trends in PM levels and associated inorganic ions in southeastern Spain. Microchem. J. 2013, 110, 81-88. [CrossRef]

12. Tao, M.; Chen, L.; Su, L.; Tao, J. Satellite observation of regional haze pollution over the North China Plain. J. Geophys. Res. Atmos. 2012, 117, D12203. [CrossRef]

13. Bréon, F.-M.; Tanré, D.; Generoso, S. Aerosol effect on cloud droplet size monitored from satellite. Science 2002, 295, 834-838. [CrossRef]

14. Luo, Y.; Zheng, X.; Zhao, T.; Chen, J. A climatology of aerosol optical depth over China from recent 10 years of MODIS remote sensing data. Int. J. Climatol. 2014, 34, 863-870. [CrossRef]

15. Shi, T.; Han, G.; Ma, X.; Gong, W.; Chen, W.; Liu, J.; Zhang, X.; Pei, Z.; Gou, H.; Bu, L. Quantifying CO2 uptakes over oceans using LIDAR: A tentative experiment in Bohai bay. Geophys. Res. Lett. 2021, 48, e2020GL091160. [CrossRef]

16. Sun, Y.; Wang, Z.; Fu, P.; Yang, T.; Jiang, Q.; Dong, H.; Li, J.; Jia, J. Aerosol composition, sources and processes during wintertime in Beijing, China. Atmos. Chem. Phys. 2013, 13, 4577-4592. [CrossRef]

17. Liu, B.; Ma, Y.; Gong, W.; Zhang, M. Observations of aerosol color ratio and depolarization ratio over Wuhan. Atmos. Pollut. Res. 2017, 8, 1113-1122. [CrossRef]

18. Shi, Y.; Liu, B.; Chen, S.; Gong, W.; Ma, Y.; Zhang, M.; Jin, S.; Jin, Y. Characteristics of aerosol within the nocturnal residual layer and its effects on surface PM2. 5 over China. Atmos. Environ. 2020, 241, 117841. [CrossRef]

19. Liu, B.; Ma, Y.; Gong, W.; Zhang, M.; Yang, J. Study of continuous air pollution in winter over Wuhan based on ground-based and satellite observations. Atmos. Pollut. Res. 2018, 9, 156-165. [CrossRef]

20. Tao, M.; Chen, L.; Wang, Z.; Tao, J.; Su, L. Satellite observation of abnormal yellow haze clouds over East China during summer agricultural burning season. Atmos. Environ. 2013, 79, 632-640. [CrossRef]

21. Tang, Y.; Han, S.; Yao, Q.; Cai, Z.; Qiu, Y.; Feng, J. Analysis of a Severe Regional Haze-fog-dust Episode over North China in Autumn by Using Multiple Observation Data. Aerosol Air Qual. Res. 2020, 20, 2211-2225. [CrossRef]

22. He, Y.; Yi, F. Dust aerosols detected using a ground-based polarization lidar and CALIPSO over Wuhan (30.5 N, 114.4 E), China. Adv. Meteorol. 2015, 2015, 536762. [CrossRef]

23. Cai, Z.; Jiang, F.; Chen, J.; Jiang, Z.; Wang, X. Weather condition dominates regional PM2. 5 pollutions in the eastern coastal provinces of China during winter. Aerosol Air Qual. Res. 2018, 18, 969-980. [CrossRef]

24. Li, Y.; Miao, Y.; Che, H.; Liu, S. On the heavy aerosol pollution and its meteorological dependence in Shandong province, China. Atmos. Res. 2021, 256, 105572. [CrossRef]

25. Wang, G.-F.; Lyu, H.-M.; Shen, J.S.; Lu, L.-H.; Li, G.; Arulrajah, A. Evaluation of environmental risk due to metro system construction in Jinan, China. Int. J. Environ. Res. Public Health 2017, 14, 1114. [CrossRef] [PubMed]

26. Li, H.; Liu, B.; Ma, X.; Jin, S.; Ma, Y.; Zhao, Y.; Gong, W. Evaluation of retrieval methods for planetary boundary layer height based on radiosonde data. Atmos. Meas. Tech. Discuss. 2021, 14, 5977-5986. [CrossRef]

27. Xu, P.; Wang, W.; Yang, L.; Zhang, Q.; Gao, R.; Wang, X.; Nie, W.; Gao, X. Aerosol size distributions in urban Jinan: Seasonal characteristics and variations between weekdays and weekends in a heavily polluted atmosphere. Environ. Monit. Assess. 2011, 179, 443-456. [CrossRef] [PubMed]

28. Liu, B.; Ma, Y.; Gong, W.; Zhang, M.; Shi, Y. The relationship between black carbon and atmospheric boundary layer height. Atmos. Pollut. Res. 2019, 10, 65-72. [CrossRef]

29. Harrison, R.M.; Yin, J. Particulate matter in the atmosphere: Which particle properties are important for its effects on health? Sci. Total Environ. 2000, 249, 85-101. [CrossRef]

30. Hunt, W.H.; Winker, D.M.; Vaughan, M.A.; Powell, K.A.; Lucker, P.L.; Weimer, C. CALIPSO lidar description and performance assessment. J. Atmos. Ocean. Technol. 2009, 26, 1214-1228. [CrossRef]

31. Liu, Z.; Liu, D.; Huang, J.; Vaughan, M.; Uno, I.; Sugimoto, N.; Kittaka, C.; Trepte, C.; Wang, Z.; Hostetler, C. Airborne dust distributions over the Tibetan Plateau and surrounding areas derived from the first year of CALIPSO lidar observations. Atmos. Chem. Phys. 2008, 8, 5045-5060. [CrossRef]

32. Omar, A.H.; Winker, D.M.; Vaughan, M.A.; Hu, Y.; Trepte, C.R.; Ferrare, R.A.; Lee, K.-P.; Hostetler, C.A.; Kittaka, C.; Rogers, R.R. The CALIPSO automated aerosol classification and lidar ratio selection algorithm. J. Atmos. Ocean. Technol. 2009, 26, 1994-2014. [CrossRef]

33. Justice, C.; Townshend, J.; Vermote, E.; Masuoka, E.; Wolfe, R.; Saleous, N.; Roy, D.; Morisette, J. An overview of MODIS Land data processing and product status. Remote Sens. Environ. 2002, 83, 3-15. [CrossRef]

34. Remer, L.A.; Kaufman, Y.; Tanré, D.; Mattoo, S.; Chu, D.; Martins, J.V.; Li, R.-R.; Ichoku, C.; Levy, R.; Kleidman, R. The MODIS aerosol algorithm, products, and validation. J. Atmos. Sci. 2005, 62, 947-973. [CrossRef]

35. Li, X.; Xia, X.; Wang, S.; Mao, J.; Liu, Y. Validation of MODIS and Deep Blue aerosol optical depth retrievals in an arid/semi-arid region of northwest China. Particuology 2012, 10, 132-139. [CrossRef]

36. Stein, A.; Draxler, R.R.; Rolph, G.D.; Stunder, B.J.; Cohen, M.; Ngan, F. NOAA's HYSPLIT atmospheric transport and dispersion modeling system. Bull. Am. Meteorol. Soc. 2015, 96, 2059-2077. [CrossRef]

37. HYSPLIT Trajectory Model-WEB. Available online: https://www.ready.noaa.gov / HYSPLIT.php (accessed on 1 July 2021).

38. Ambient Air Quality Standards. Available online: https://www.mee.gov.cn/ywgz/fgbz/bz/bzwb/dqhjbh/dqhjzlbz/201203/t2 0120302_224165.shtml (accessed on 29 September 2021). 
39. Gao, J.; Tian, H.; Cheng, K.; Lu, L.; Zheng, M.; Wang, S.; Hao, J.; Wang, K.; Hua, S.; Zhu, C. The variation of chemical characteristics of PM2. 5 and PM10 and formation causes during two haze pollution events in urban Beijing, China. Atmos. Environ. 2015, 107, 1-8. [CrossRef]

40. Ravindra, K.; Singh, T.; Sinha, V.; Sinha, B.; Paul, S.; Attri, S.; Mor, S. Appraisal of regional haze event and its relationship with PM2. 5 concentration, crop residue burning and meteorology in Chandigarh, India. Chemosphere 2021, 273, 128562. [CrossRef] [PubMed]

41. Zhao, X.; Zhao, P.; Xu, J.; Meng, W.; Pu, W.; Dong, F.; He, D.; Shi, Q. Analysis of a winter regional haze event and its formation mechanism in the North China Plain. Atmos. Chem. Phys. 2013, 13, 5685-5696. [CrossRef]

42. Zhang, H.; Ma, X.; Han, G.; Xu, H.; Shi, T.; Zhong, W.; Gong, W. Study on Collaborative Emission Reduction in Green-House and Pollutant Gas Due to COVID-19 Lockdown in China. Remote Sens. 2021, 13, 3492. [CrossRef]

43. Yang, J.; Yang, S.; Zhang, Y.; Shi, S.; Du, L. Improving characteristic band selection in leaf biochemical property estimation considering interrelations among biochemical parameters based on the PROSPECT-D model. Opt. Express 2021, 29 , 400-414. [CrossRef]

44. Yang, Y.; Liu, X.; Qu, Y.; Wang, J.; An, J.; Zhang, Y.; Zhang, F. Formation mechanism of continuous extreme haze episodes in the megacity Beijing, China, in January 2013. Atmos. Res. 2015, 155, 192-203. [CrossRef]

45. Gui, K.; Che, H.; Chen, Q.; An, L.; Zeng, Z.; Guo, Z.; Zheng, Y.; Wang, H.; Wang, Y.; Yu, J. Aerosol optical properties based on ground and satellite retrievals during a serious haze episode in December 2015 over Beijing. Atmosphere 2016, 7, 70. [CrossRef]

46. Yang, Y.; Liu, X.; Qu, Y.; An, J.; Jiang, R.; Zhang, Y.; Sun, Y.; Wu, Z.; Zhang, F.; Xu, W. Characteristics and formation mechanism of continuous hazes in China: A case study during the autumn of 2014 in the North China Plain. Atmos. Chem. Phys. 2015, 15, 8165-8178. [CrossRef]

47. Pachauri, T.; Singla, V.; Satsangi, A.; Lakhani, A.; Kumari, K.M. Characterization of major pollution events (dust, haze, and two festival events) at Agra, India. Environ. Sci. Pollut. Res. 2013, 20, 5737-5752. [CrossRef]

48. Tao, M.; Chen, L.; Xiong, X.; Zhang, M.; Ma, P.; Tao, J.; Wang, Z. Formation process of the widespread extreme haze pollution over northern China in January 2013: Implications for regional air quality and climate. Atmos. Environ. 2014, 98, 417-425. [CrossRef]

49. Liu, B.; Gong, W.; Ma, Y.; Zhang, M.; Yang, J.; Zhang, M. Surface aerosol optical properties during high and low pollution periods at an urban site in central China. Aerosol Air Qual. Res. 2018, 18, 3035-3046. [CrossRef]

50. Fu, S.; Xie, C.; Zhuang, P.; Tian, X.; Zhang, Z.; Wang, B.; Liu, D. Study of persistent foggy-hazy composite pollution in winter over Huainan through ground-based and satellite measurements. Atmosphere 2019, 10, 656. [CrossRef]

51. Qi, B.; Hu, D.; Che, H.; Du, R.; Wu, Y.; Xia, X.; Zha, B.; Liu, J.; Niu, Y.; Wang, H. Seasonal variation of aerosol optical properties in an urban site of the Yangtze Delta Region of China. Aerosol Air Qual. Res. 2016, 16, 2884-2896. [CrossRef]

52. Zhao, H.; Che, H.; Wang, Y.; Dong, Y.; Ma, Y.; Li, X.; Hong, Y.; Yang, H.; Liu, Y.; Wang, Y. Aerosol vertical distribution and typical air pollution episodes over northeastern China during 2016 analyzed by ground-based lidar. Aerosol Air Qual. Res. 2018, 18, 918-937. [CrossRef]

53. Wang, Z.; Liu, C.; Hu, Q.; Dong, Y.; Liu, H.; Xing, C.; Tan, W. Quantify the Contribution of Dust and Anthropogenic Sources to Aerosols in North China by Lidar and Validated with CALIPSO. Remote Sens. 2021, 13, 1811. [CrossRef]

54. Zhang, M.; Ma, Y.; Gong, W.; Liu, B.; Shi, Y.; Chen, Z. Aerosol optical properties and radiative effects: Assessment of urban aerosols in central China using 10-year observations. Atmos. Environ. 2018, 182, 275-285. [CrossRef]

55. Liu, C.; Yang, L.; Che, H.; Xia, X.; Zhao, H.; Wang, H.; Gui, K.; Zheng, Y.; Sun, T.; Li, X. Aerosol optical properties over an urban site in Central China determined using ground-based sun photometer measurements. Aerosol Air Qual. Res. 2019, 19, 620-638. [CrossRef]

56. Cheng, H.; Gong, W.; Wang, Z.; Zhang, F.; Wang, X.; Lv, X.; Liu, J.; Fu, X.; Zhang, G. Ionic composition of submicron particles (PM1. 0) during the long-lasting haze period in January 2013 in Wuhan, central China. J. Environ. Sci. 2014, 26, 810-817. [CrossRef]

57. Sun, Y.; Zhuang, G.; Tang, A.; Wang, Y.; An, Z. Chemical characteristics of PM2. 5 and PM10 in haze- fog episodes in Beijing. Environ. Sci. Technol. 2006, 40, 3148-3155. [CrossRef] [PubMed] 